\title{
PRODUÇÃO DE SEDIMENTO EM CAMINHOS DE ANIMAIS EM SISTEMA DE FAXINAL NA REGIÃO CENTRO-SUL DO ESTADO DO PARANÁ.
}

\section{SEDIMENT PRODUCTION ON ANIMALS TRAILS IN FAXINAL SYSTEM IN SOUTH CENTRAL REGION OF THE STATE OF PARANÁ.}

Valdemir Antoneli
Universidade Estadual do Centro-Oeste - UNICENTRO - Departamento de Geografia Campus de Irati- Pr. PR 153 Km
7 - Riozinho - CEP 84500-000 Irati - PR - e-mail vaantoneli@gmail.com

João Anésio Bednarz

Curso de Pós Graduação em Geografia da Universidade Estadual do Centro-Oeste - UNICENTRO - Guarapuava - PR e-mailjhonesguamirim@hotmail.com

Edivaldo Lopes Thomaz

Universidade Estadual do Centro-Oeste - UNICENTRO - Departamento de Geografia - Rua Camargo Varela de Sá, 03 Vila Carli - CEP 85040-080 Guarapuava - PR - e-mail: edivaldo.thomaz@pq.cnpq.br

\section{Informações sobre o Artigo}

Data de Recebimento:

$24 / 12 / 2011$

Data de Aprovação: $14 / 04 / 2013$

\section{Palavras-chave:}

Bio-erosão, conectividade, caminhos preferenciais; Faxinal; sazonalidade

\section{Keywords:}

Bio-erosion, connectivity, preferential pathways; Faxinal; seasonality

\begin{abstract}
Resumo
Este artigo tem como objetivo avaliar a produção de sedimentos oriunda dos caminhos preferenciais dos animais no Faxinal Marmeleiro de Cima, Município de Rebouças, Paraná. O Sistema de Faxinal é uma forma de uso e ocupação característica da região Centro-Sul do Estado do Paraná. Neste sistema, existe o criadouro comunitário, onde os animais são criados de forma extensiva sem limites entre as propriedades. A constante mobilização dos animais, tanto nas áreas de pastagens como nas áreas de floresta do Faxinal, acabam dando origem a caminhos preferenciais que atuam como canais efêmeros em períodos de chuva, servindo como conectores entre os sedimentos do sistema (vertentes) com os canais fluviais. Foram identificados 16 perfis, sendo 8 (oito) perfis em caminhos preferenciais que dão acesso aos corpos hídricos (zona ripária). Os demais foram identificados em caminhos preferenciais existentes nas áreas de pastagens na vertente (terras altas). Utilizou-se da técnica de perfis transversais, (profilometers) para avaliar a perda de solo nestes caminhos. Ao término, do monitoramento, foi constatado que os perfis que dão acesso aos rios apresentaram maior erosão $\left(6,7 \mathrm{~kg} / \mathrm{m}^{2}\right)$, enquanto que os caminhos preferenciais das pastagens ao longo da vertente (terras altas) indicaram uma erosão em torno de $4,9 \mathrm{~kg} / \mathrm{m}^{2}$.
\end{abstract}

\section{Abstract}

This paper aims to evaluate the production of sediments coming from the preferential paths of animals in Faxinal Marmeleiro de Cima, County of Rebouças, Parana. The Faxinal system is a characteristic way of use and occupancy in the South Central region of Paraná 
State. In this system, there is the communitarian breeding, where animals are raised in an extensive way with no boundaries between properties. The constant mobilization of animals, both in areas of grassland and areas of Faxinal forest, eventually give rise to preferential paths that act as ephemeral channels during periods of rain, serving as connectors between the system sediments (strands) with fluvial channels . 16 profiles were identified, 8 (eight) profiles in paths that give preferential access to water bodies (riparian zone). The others were identified in existing preferential paths in the slope (high lands). The technique of transversal profiles (profilometers) was used to evaluate the soil loss in these paths. At the end of the monitoring, it was found that the profiles that provide access to rivers showed higher erosion $\left(6.7 \mathrm{~kg} / \mathrm{m}^{2}\right)$, while the preferential paths along the slope (up lands) indicated an erosion of around $4.9 \mathrm{~kg} / \mathrm{m}^{2}$.

\section{Introdução}

Os faxinais são comunidades tradicionais que existem na região Centro-Sul do Paraná, sendo reconhecidos por sua territorialidade específica (Decreto Federal 10.408/2006 Comissão de Desenvolvimento Sustentável das Comunidades Tradicionais). Sua formação data do início do século XIX, a partir de um processo que fez emergir um campesinato livre, auto definido como faxinalense. $\mathrm{O}$ faxinal é organizado em terras de criatório comum de animais, associados à paisagem florestal nativa da região Centro-Sul do estado do Paraná em áreas de ocorrência da Mata de Araucária (Ombrófila Mista).

O Sistema Faxinal é definido como um sistema de produção camponês tradicional, característico da região Centro-Sul do Paraná, que tem como traço marcante o uso coletivo da terra para produção animal e a conservação ambiental. Fundamenta-se na integração de três componentes: a) produção animal coletiva, à solta, através dos criadouros comunitários; b) produção agrícola - policultura alimentar de subsistência para consumo e comercialização; c) extrativismo florestal de baixo impacto - manejo de erva-mate, araucária e outras espécies nativas (CHANG, 1986).

Dentro desta perspectiva, o Sistema de Faxinal pode ser entendido como um sistema agrosilvopastoril. No entanto, quando investigado apenas as inter-relações existentes nas áreas de criadouro comunitário (áreas de criar), este sistema pode ser caracterizado como silvopastoril, por associar criação de animais de forma extensiva com exploração vegetal.

Em geral, a organização do sistema se dá pelo cercamento de toda a área do Faxinal, dentro do qual funciona o criadouro comum, onde todos os proprietários têm o direito de criar seus animais (aves, bovino, suíno, equino, etc.) a solta, não havendo cercas ou barreiras entre uma propriedade e outra (CHANG, 1986; DORETTO, 1992; CARVALHO, 1994; ANTONELI, 2007). Mesmo os agricultores que apenas possuem suas casas dentro do sistema, também lhes são reservado o direito de criar animais dentro da área. Significa, portanto que não necessariamente precisa ser dono de terras dentro do Faxinal para criar seus rebanhos.

Essas áreas, geralmente são formadas por vales com relevo pouco dissecado e presença de cursos de água, abrigando um ambiente florestal alterado pelo pastoreio extensivo
(CHANG, 1986), sendo esse o principal motivo da degradação do solo dentro do sistema (ANTONELI, 2011).

O sistema de Faxinal é o principal responsável pela preservação das últimas áreas florestais, de uma cultura própria de exploração da terra e de modelo sócio-econômico. Mas atrelado a esses pontos positivos, há também, problemas relacionados à degradação da área causada por essa forma de criação dos animais. A forma de criação sem restrição de propriedades (soltos) é apontada como o principal fator de erosão e degradação do solo, devido ao constante pisoteio desses animais. O pisoteio acaba originando caminhos preferenciais (trilhas), nas áreas de pastagens ao longo da vertente e áreas próximas de cercas e de cursos de água (zona ripária).

Durante a ocorrência de eventos pluviométricos, esses caminhos preferenciais se tornam canais efêmeros, que conduzem água e sedimentos oriundos das vertentes e dos próprios caminhos preferenciais para as áreas mais baixas ou para os cursos de água, tornando-se importantes conectores dos sedimentos das vertentes com os corpos hídricos (THOMAZ e DIAS, 2009), auxiliando na taxa de transferência dos sedimentos.

O pastoreio em áreas de faxinais resulta em efeitos de ordem direta e indireta, além disso, afetam diferentes partes do sistema geomorfológico como: as partes altas das vertentes e zonas ripárias (THOMAZ e DIAS, 2009). Portanto, a ação dos animais que são criados de forma extensiva vai além dos processos geomorfológicos, pois englobam processos hidrológicos e ecológicos entre outros. Por isso, segundo os autores, essas trilhas originadas ao longo da vertente são de grande interesse para a geomorfologia fluvial devido à produção e transferência de sedimento da própria vertente para o canal fluvial.

Os animais em pastejo exercem diferentes efeitos sobre a pastagem como: a desfolha (BOOYSEN et al., 1963), pisoteio e compactação (SNAYDON, 1981; THOMAZ e DIAS, 2009; ANTONELI, 2011), exposição do solo (PERUCELI e ANTONELI, 2010) e a excreção (MONTEIRO e WERNER, 1989)

Neste contexto, Coaldrake et al., (1976), afirmam que em uma pastagem as plantas diferem em suas respostas quanto a estes efeitos, portanto, há uma interação dinâmica entre a pressão de pastoreio e a composição de espécies na pastagem. Pesquisas desenvolvidas por Holt et al., (1996); Muller et al., 
(2001); Thomaz e Dias, (2009), condicionam o agravamento das condições físicas de solos sob pastagem ao constante pisoteio dos animais, promovendo a compactação do solo, que é verificada por meio do aumento da densidade aparente, da microporosidade e da resistência do solo à penetração. Estes processos atuam na redução da infiltração da água no solo, que culminam com maior percentual de escoamento superficial.

No entanto, são poucas as pesquisas realizadas acerca da perda de solo em sistemas silvopastoris, (ARAÚJO FILHO e CARVALHO, 2001; COGO et al., 2003). Quando se trata do sistema silvopastoril de Faxinais com criadouros comuns, as pesquisas são ainda mais restritas, por este Sistema ser característico apenas da região Centro-Sul do Paraná (THOMAZ e DIAS 2009; ANTONELI, 2011).

Neste contexto, nota-se que há uma escassez de pesquisas em perdas de solos nos caminhos preferenciais dos animais. Portanto, esta pesquisa teve como objetivo avaliar as perdas de solo nos caminhos preferenciais nas áreas de pastagens ao longo da vertente (terras altas) e caminhos preferenciais nas zonas ripárias (terras baixas) em uma Floresta Ombrófila Mista associada ao Sistema de Faxinal. Pressupõe-se que os animais exercem certa influência nas perdas de solos nos caminhos preferenciais, por intensificarem o pisoteio nestes caminhos de forma sazonal.

\section{Caracterização da área de estudo}

O Faxinal Marmeleiro de Cima está localizado na parte Nordeste do município de Rebouças está situado na região Centro-Sul do Estado do Paraná, a 167,87 km da capital do Estado, Curitiba. (Figura 1).

$\mathrm{Na}$ área de plantar é desenvolvido o plantio de soja e milho nas terras menos declivosas (agricultura mecanizada) e cultivo de feijão no sistema de roça de coivara (roça tropical de subsistência). Outros faxinalenses sobrevivem da própria criação de animais a solta (criação de animais de forma extensiva), o qual requer pouca mão de obra, dedicando seu tempo como trabalhadores volantes (bóia-fria) no plantio e colheita de batata, feijão tabaco, dentre outras atividades.

Segundo informações pessoais dos faxinalenses (2011), há uma estimativa da população de animais, de aproximadamente de 225 suínos (22\%), 40 equinos (4\%), 58 bovinos (6\%) e 512 aves (49\%), os quais são criados soltos (criadouro comum) em uma área de 60,5 ha.

A estimativa unidade animal por hectare (UA/ha), na área de estudos é de 3,71UA/ha de suínos, 0,66 UA/ha para os equinos, 0,91 UA/ha para os bovinos e 8,4 UA/ha para as aves.

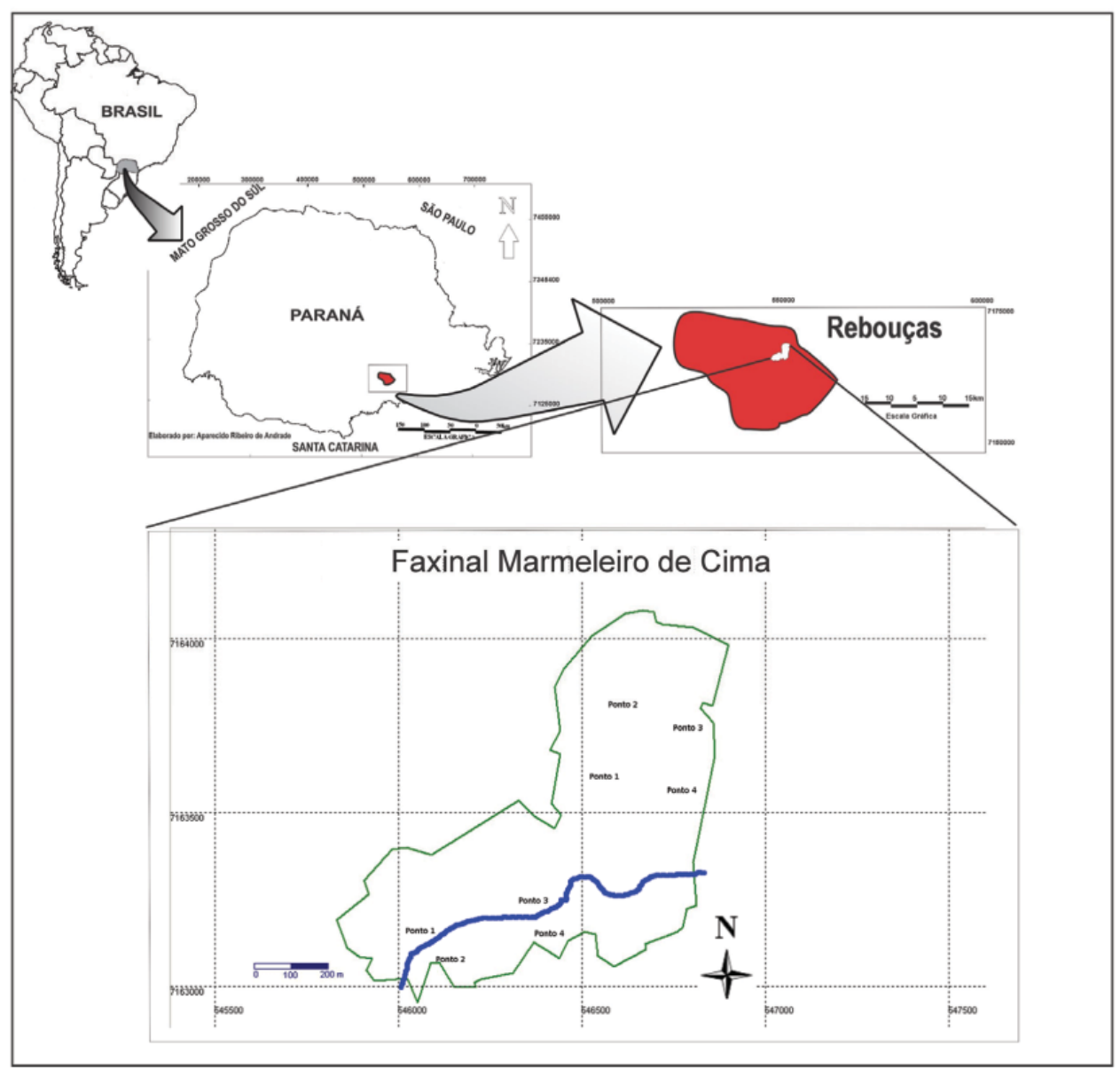

Figura 1 - Caracterização da área de estudo 
A fitossociologia da área de estudo indica que as famílias que apresentam a maior percentagem no número de indivíduos são: Myrtaceae (17,7\%), dentre elas destacamse: guabirobeira, pitangueira, cerejeira do mato, uvaia e sete capote. Flacourtiaceae (15,5\%), como as diversas espécies de guaçatungas. Fabaceae e Aquifoliaceae (8,8\%), como o timbó, farinha seco, caúna e erva mate. Lauraceae e Euphorbiaceae (6,6\%), como as diversas espécies de canela e imbuia e Sapindaceae (4,4\%) como o miguel-pintado e vacun, as demais famílias apresentaram menor representatividade $(<1 \%)$ (ALBUQUERQUE, 2009). A área apresenta um número de 445 indivíduos por hectare. O DAP (Diâmetro da Altura do Peito) médio da comunidade arbórea é de $20 \mathrm{~cm}$, sendo que 79,2\% do número de indivíduos por hectare indicam diâmetro entre $10 \mathrm{~cm}$ e $25 \mathrm{~cm}$, e $14,2 \%$ entre 25 e $35 \mathrm{~cm}$.

Segundo MINEROPAR (2006), a área de estudos está inserida na Sub-unidade morfoescultural denominada Planalto de São Mateus do Sul, situada no Segundo Planalto Paranaense. Apresenta dissecação baixa e ocupa uma área de $1.515,12 \mathrm{~km}^{2}$. A classe de declividade predominante é menor que $6 \%$ em uma área de 1.063,54 $\mathrm{km}^{2}$.

Em relação ao relevo, indica uma amplitude de 240 metros variando entre 760 metros (mínima) a 1.000 metros (máxima). As formas predominantes do relevo são topos aplainados, vertentes retilíneas e vales em "V". A formação geológica da área de estudo é composta pela Formação Serra Alta que se caracteriza pela composição de lamitos e folhelhos, cinzentos, escuros, maciços e microlaminados, originários de depósitos de plataforma epinerítica (MINEROPAR, 2006).
Essas características físicas possibilitam o surgimento de solos pouco desenvolvidos, predominando os Neossolo Regolítico e Litólico e Cambissolo. Segundo Lepsch et al., (1983), os solos com tais características enquadram-se no uso para pastagens e florestas, sendo inadequados para a agricultura mecanizada. Destaca-se, que os caminhos preferenciais nas terras altas indicam um Cambissolo, enquanto que nas terras baixas, há uma transição entre Cambissolo e Gleyssolo.

O clima da região segundo classificação de Köppen é $\mathrm{Cfb}$ - Subtropical úmido, com temperaturas médias anuais entre $17^{\circ}$ e $19^{\circ} \mathrm{C}$, sendo o mês mais quente inferior a $23^{\circ} \mathrm{C}$ e o mês mais frio superior a $-3^{\circ} \mathrm{C}$, apresentando entre 5 a 10 geadas no ano (MAACK, 1968). A precipitação média anual é de $1600 \mathrm{~mm}$, com elevada umidade relativa do ar (superior a $70 \%$, em média) e temperatura média anual de aproximadamente $18^{\circ} \mathrm{C}$ (SUDERHSA, 1998).

\section{Material e método}

\section{Estimativa de perda de solo em caminhos preferenciais}

Os caminhos preferenciais monitorados foram identificados após atividades de campo. Considerou-se aqueles caminhos existentes nas vertentes (terras altas) e nas áreas baixas próximos aos rios (zona ripária). Monitorou-se 8 caminhos, sendo 4 em cada área. Foram realizados 16 perfis sendo 8 (oito) perfis nas vertentes sob pastagens (terras altas) e 8 (oito) nas áreas mais baixas. (Tabela 1).

\section{Tabela 1 - Características dos caminhos preferenciais monitorados}

\begin{tabular}{|c|c|c|c|c|c|}
\hline Localização & $\begin{array}{l}\mathrm{N}^{\mathrm{o}} \text { de caminhos } \\
\text { monitorados }\end{array}$ & $\begin{array}{l}\text { Comprimento } \\
\text { Médio de cada caminho (m) }\end{array}$ & Largura Média (cm) & *Área de contribuição $\left(\mathrm{m}^{2}\right)$ & $\begin{array}{l}\text { Declividade } \\
\text { Média (\%) }\end{array}$ \\
\hline $\begin{array}{l}\text { Pastagem } \\
\text { Áreas altas }\end{array}$ & 4 & $20 \pm 2,5$ & $40 \pm 5,1$ & $8 \pm 2.7$ & 9 \\
\hline $\begin{array}{l}\text { Zona ripária } \\
\text { Áreas baixas }\end{array}$ & 4 & $6 \pm 1,7$ & $150 \pm 13,2$ & $9 \pm 4.2$ & 14 \\
\hline
\end{tabular}

Nota: *A área de contribuição, refere-se à média estimada entre os caminhos monitorados

Por meio da tabela 1 , nota-se que os caminhos preferenciais na vertente (terras altas) apresentam maior comprimento e menor largura, já os caminhos preferên- cias que dão acesso aos corpos hídricos apresentam menor comprimento, mas com largura e declividade maiores (Figura 2). 

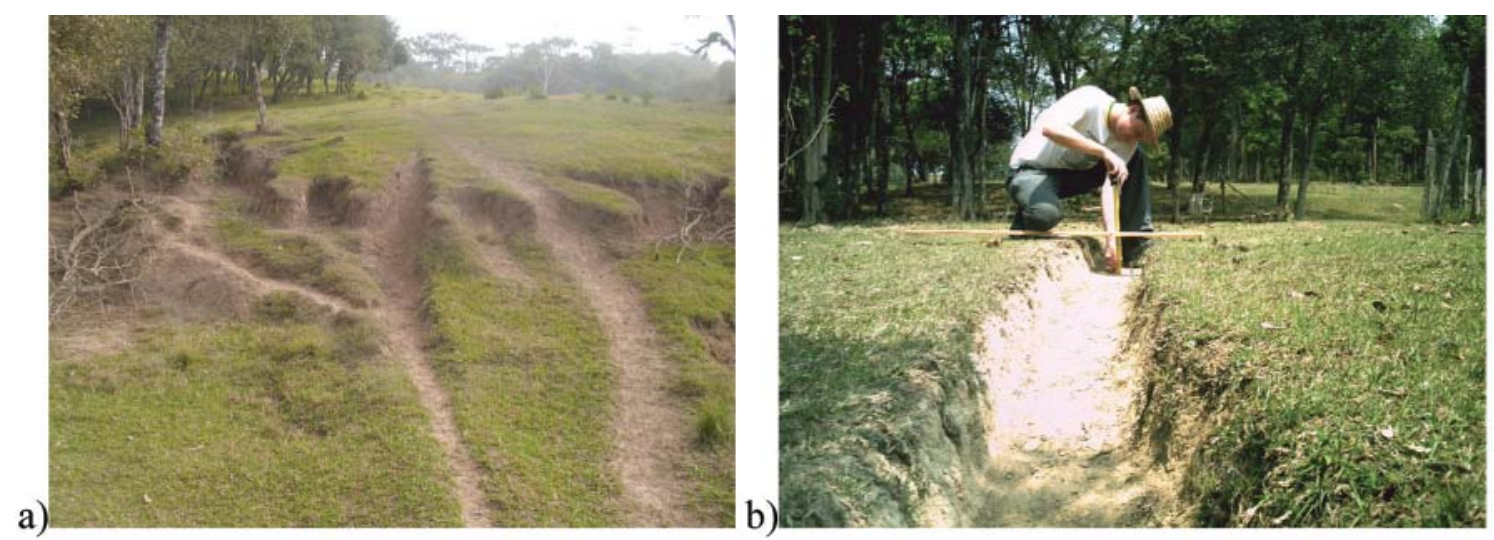

Figura 2 - a) características dos caminhos preferenciais; b) mensuração do rebaixamento da superficie por meio de perfis transversais nos caminhos preferenciais na vertente (terras altas).

Para avaliar a perda de solos nestes caminhos preferenciais foram aplicadas técnicas de mensuração volumétricas (HUDSON, 1993; THOMAZ, 2008; ANTONELI, 2011).

Dentre as mensurações dinâmicas, utilizou-se da técnica de perfis transversais, para monitorar o rebaixamento e/ou acúmulo de solo nos caminhos preferenciais. Os perfis transversais (profilometers) consistiram na utilização de um fio de nylon, devidamente graduado o qual é amarrado em duas hastes fixas nas margens dos caminhos preferenciais (permanecem fixas ao longo de todas as coletas). Com uma trena (régua) faz-se a mensuração de $10 \mathrm{em} 10 \mathrm{~cm}$ entre o fio de nylon e a superfície que está sendo mensurada (Figura 3). Ao término do monitoramento, calculou-se o rebaixamento da superfície em centímetros.

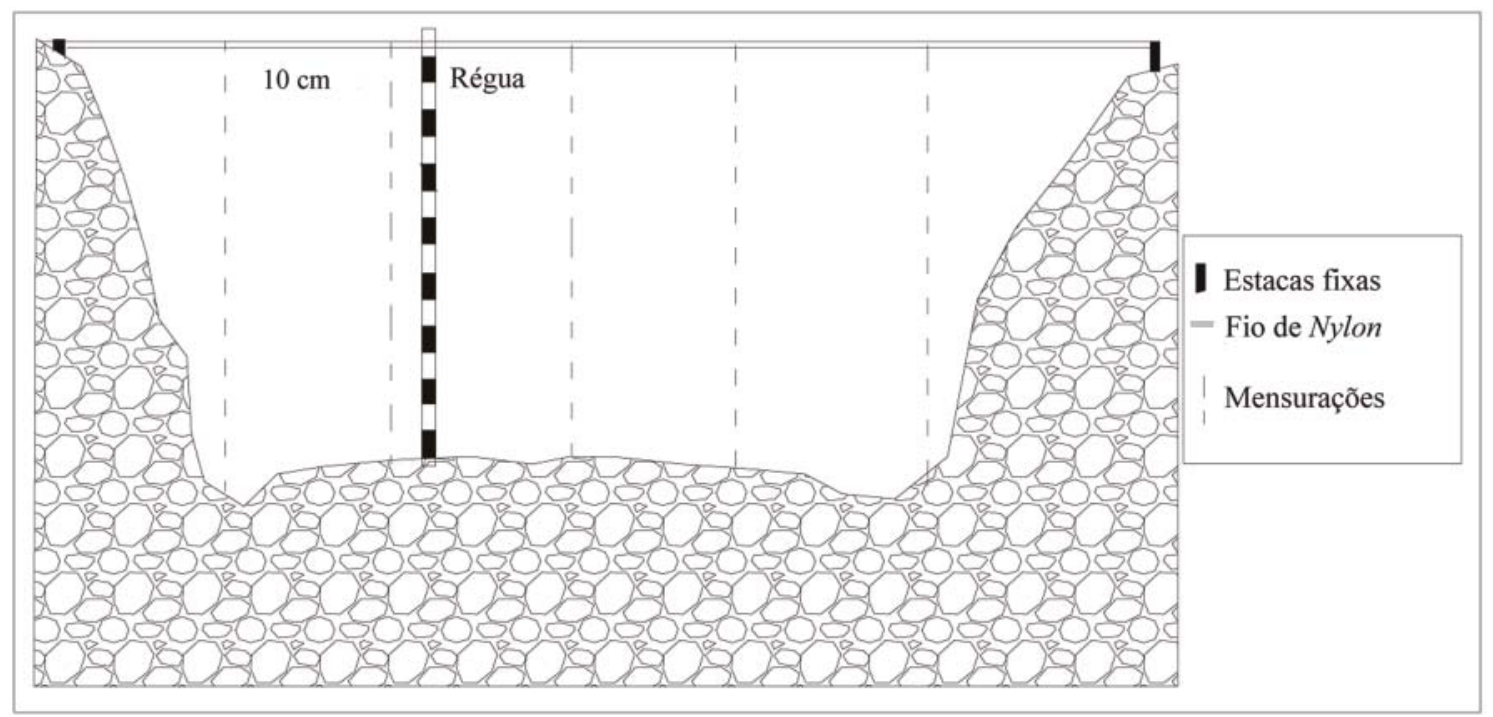

Figura 3- Esquema ilustrativo da realização dos perfis transversais nos caminhos preferenciais.

\section{Estimativa da densidade aparente do solo}

Para calcular a perda de solo nos caminhos preferenciais na seção monitorada, foi preciso antes identificar a densidade aparente do solo. Para este procedimento, foram coletadas 30 amostras de solo ao longo do monitoramento, sendo 15 amostras em cada tipo de caminho preferencial.
A densidade foi estimada pela técnica do anel volumétrico (cilindro de metal) de $100 \mathrm{~cm}^{3}$. Após as análises laboratoriais do solo coletado (pesagem e secagem) foi estimado o volume do material coletado, servindo de base para identificar os totais de solo em $\mathrm{g} / \mathrm{cm}^{3}$.

Para calcular a densidade aparente do solo seco, utilizou-se da equação 1: 


$$
D_{s}=\frac{M_{s}}{V}
$$

(equação 1)

Sendo:

$\mathrm{D}_{\mathrm{s}}=$ Densidade aparente do solo seco $\left(\mathrm{g} / \mathrm{cm}^{3}\right)$

$\mathrm{M}_{\mathrm{s}}=$ Massa seca $(\mathrm{g})$

$\mathrm{V}=$ volume do anel $\left(\mathrm{cm}^{3}\right)$

De posse dos dados de densidade aparente do solo, calculou-se a perda de solo dos caminhos preferenciais. Como as mensurações foram realizadas sempre no mesmo local, ao término do monitoramento obteve-se uma medida inicial e uma medida final em cada ponto (de $10 \mathrm{em} 10 \mathrm{~cm}$ entre o fio de nylon e solo). Neste caso subtraíram-se os valores iniciais (primeira mensuração de cada ponto), dos valores finais (última mensuração de cada ponto).

Para calcular a perda de solo dos caminhos preferenciais, utilizou-se a equação 2 :

$$
\begin{aligned}
& \left.\quad P=\sum^{-1} \dot{n}-\sum^{-1} f \times \mathrm{D}_{\mathrm{s}} \quad \text { (equação } 2\right) \\
& \text { Onde: } \\
& \text { P= Perda de solo }(\mathrm{kg} / \mathrm{m}) \\
& \sum^{-1} \dot{n}=\text { Somatório inicial da área do perfil }(\mathrm{cm}) \\
& \sum_{\mathrm{D}_{\mathrm{s}}=\text { Densidade aparente }\left(\mathrm{g} / \mathrm{cm}^{3}\right)}^{-1} f=\text { Somatório final da área do perfil }(\mathrm{cm})
\end{aligned}
$$

As mensurações foram realizadas a cada dois meses, sendo realizada de junho de 2009 a abril de 2010. Destaca-se que a primeira coleta dos dados foi realizada no mês de abril de 2009. Ao longo do monitoramento ocorreram 117 chuvas, sendo que o mês de janeiro de 2010 indicou maior número (16 chuvas) e o mês de maio de 2009 indicou menor ocorrência
(7 chuvas). As quais foram mensuradas, por meio de um pluviômetro manual instalado na área de monitoramento

\section{Mensuração da compactação do topo do solo}

Para avaliar a compactação do solo, utilizou-se um penetrômetro de bolso com força máxima de $4,5 \mathrm{kgf} / \mathrm{cm}^{2}$. Destaca-se que foram realizadas campanhas de coleta da compactação no leito dos caminhos preferenciais. Os resultados foram transformados em MPa. As campanhas de coletas foram realizadas a cada mensuração dos perfis transversais. Foram coletadas em torno de 30 amostras em cada caminho preferencial, totalizando 240 amostras de compactação a cada mensuração dos perfis transversais. Sendo 120 amostras em cada tipo de caminho preferencial (terras altas e terras baixas). Ao término da pesquisa, totalizou-se 1440 amostras de compactação de solo nos caminhos preferenciais.

\section{Análise estatística}

Após tabulação dos dados, foi aplicada análise estatística descritiva como: média, desvio padrão e coeficiente de variação.

\section{Resultados e discussões}

\section{Perda de solo em caminhos preferenciais na vertente (terras altas)}

A concentração do pisoteio dos animais em determinados locais promovem alterações como: redução da infiltração, aumento do escoamento, além da concentração do fluxo nos caminhos preferenciais. As alterações desses processos promovem reações em cadeia que vão refletir em uma intensificação da entrada de sedimentos das vertentes

\begin{tabular}{|c|c|c|c|c|c|c|c|c|c|c|}
\hline Coletas & $\begin{array}{c}* \mathrm{P} 1 \\
\left(\mathrm{~kg} / \mathrm{m}^{2}\right)\end{array}$ & $\begin{array}{c}\text { P } 2 \\
\left(\mathrm{~kg} / \mathrm{m}^{2}\right)\end{array}$ & $\begin{array}{c}\text { P 3 } \\
\left(\mathrm{kg} / \mathrm{m}^{2}\right)\end{array}$ & $\begin{array}{c}\text { P } 4 \\
\left(\mathrm{~kg} / \mathrm{m}^{2}\right)\end{array}$ & $\begin{array}{c}\text { P 5 } \\
\left(\mathrm{kg} / \mathrm{m}^{2}\right)\end{array}$ & $\begin{array}{c}\text { P 6 } \\
\left(\mathrm{kg} / \mathrm{m}^{2}\right)\end{array}$ & $\begin{array}{c}\text { P7 } \\
\left(\mathrm{kg} / \mathrm{m}^{2}\right)\end{array}$ & $\begin{array}{c}\text { P 8 } \\
\left(\mathrm{kg} / \mathrm{m}^{2}\right)\end{array}$ & $\begin{array}{c}\text { Média } \\
\left(\mathrm{kg} / \mathrm{m}^{2}\right)\end{array}$ & $\begin{array}{c}\text { Chuva } \\
(\mathrm{mm})\end{array}$ \\
\hline Jun/09 & 0,4 & 0,1 & 0,5 & 0,5 & 0,7 & 0,6 & 0,1 & 0,0 & 0,4 & 127 \\
\hline Ago/09 & 1,1 & 1,0 & 1,8 & 1,9 & 1,2 & 1,5 & 1,7 & 0,8 & 1,4 & 302 \\
\hline Out/09 & 2,1 & 1,3 & 2,5 & 2,3 & 1,1 & 1,8 & 2,3 & 1,5 & 1,9 & 463 \\
\hline Dez/09 & 0,0 & 0,4 & 0,1 & 1,0 & 0,7 & 1,0 & 0,8 & 0,8 & 0,6 & 297 \\
\hline Fev/10 & 0,4 & 0,4 & 0,0 & 0,5 & 0,6 & 0,2 & 0,8 & 1,1 & 0,5 & 261 \\
\hline Abr/10 & 0,0 & 0,0 & 0,4 & 0,0 & 0,6 & 0,6 & 0,0 & 0,0 & 0,2 & 218 \\
\hline Perda de solo $\left(\mathrm{kg} / \mathrm{m}^{2}\right)$ & 3,8 & 3,1 & 5,3 & 6,2 & 5,0 & 5,7 & 5,8 & 4,2 & 4,9 & 1668 \\
\hline
\end{tabular}
com os canais fluviais.

No entanto nas áreas de criadouro comum, no sistema de Faxinal, nota-se que há uma variação nas perdas de solos em determinados períodos do ano. Essa alternância pode ser resultado da mobilização dos animais ao longo das estações (Tabela 2).

Tabela 2 - Perda de solo em caminhos preferenciais nas vertentes (terras altas).

Nota - *P (Perfil transversal); Densidade aparente do solo para estimativa de perda de solo foi de 1,21 $00,25(n=15)$. 
Nota-se que a perda de solo ao longo do monitoramento apresentou variações significativas, sendo que as menores perdas foram registradas nos meses de junho e abril, que coincidem com o período mais frio da área de estudos. O período mais frio da área de estudos já havia sido analisado por Andrade et al., (2012). Já as maiores perdas foram verificadas entre agosto e dezembro. A perda média mensal de solo dos caminhos preferenciais na vertente (terras altas) ao término do monitoramento foi de $4,9 \mathrm{~kg} / \mathrm{m}^{2}$. Destaca-se que a maior perda de solo registrada, condiz com o maior volume de precipitação, onde os meses de agosto e outubro indicaram rebaixamento de $1,4 \mathrm{~kg} / \mathrm{m}^{2} \mathrm{e} 1,9 \mathrm{~kg} / \mathrm{m}^{2}$ com uma precipitação de $302 \mathrm{~mm}$ e $463 \mathrm{~mm}$ respectivamente.

\section{Perda de solo em caminhos preferenciais da zona ripária (terras baixas) e comportamento dos animais}

Na sequência foram identificadas as perdas de solo nos caminhos preferenciais que dão acesso aos corpos hídricos (Tabela 3). Através de caminhamentos pela área de estudos ao longo do monitoramento, notou-se que estes caminhos sofrem maior pressão nos período em que a temperatura é mais elevada (primavera e verão), principalmente pelos suínos, por utilizarem estes corpos hídricos não apenas para a dessedentação, mas para banho.

Tabela 3 - Perda de solo em caminhos preferenciais na zona ripária (terras baixas).

\begin{tabular}{|c|c|c|c|c|c|c|c|c|c|c|}
\hline Coletas & $\begin{array}{c}\text { P } 1 \\
\left(\mathrm{~kg} / \mathrm{m}^{2}\right)\end{array}$ & $\begin{array}{c}\text { P } 2 \\
\left(\mathrm{~kg} / \mathrm{m}^{2}\right)\end{array}$ & $\begin{array}{c}\text { P 3 } \\
\left(\mathrm{kg} / \mathrm{m}^{2}\right)\end{array}$ & $\begin{array}{c}\mathrm{P} 4 \\
\left(\mathrm{~kg} / \mathrm{m}^{2}\right)\end{array}$ & $\begin{array}{c}\text { P } 5 \\
\left(\mathrm{~kg} / \mathrm{m}^{2}\right)\end{array}$ & $\begin{array}{c}\text { P 6 } \\
\left(\mathrm{kg} / \mathrm{m}^{2}\right)\end{array}$ & $\begin{array}{c}\text { P7 } \\
\left(\mathrm{kg} / \mathrm{m}^{2}\right)\end{array}$ & $\begin{array}{c}\text { P 8 } \\
\left(\mathrm{kg} / \mathrm{m}^{2}\right)\end{array}$ & $\begin{array}{c}\text { Total } \\
\left(\mathrm{kg} / \mathrm{m}^{2}\right)\end{array}$ & $\begin{array}{c}\text { Chuva } \\
\mathrm{mm}\end{array}$ \\
\hline Jun/09 & 0,0 & 0,6 & 0,0 & 0,0 & 1,0 & 0,8 & 0,5 & 0,6 & 0,4 & 127 \\
\hline Ago/09 & 0,8 & 0,4 & 0,6 & 1,1 & 1,5 & 1,3 & 1,5 & 1,1 & 1,0 & 302 \\
\hline Out/09 & 1,6 & 1,8 & 0,6 & 2,8 & 1,8 & 3,1 & 2,8 & 2,3 & 2,1 & 463 \\
\hline Dez/09 & 1,7 & 1,1 & 1,3 & 1,1 & 0,8 & 1,1 & 1,5 & 1,8 & 1,3 & 297 \\
\hline $\mathrm{Fev} / 10$ & 2,5 & 1,0 & 0,6 & 0,6 & 1,1 & 2,1 & 1,1 & 1,7 & 1,3 & 261 \\
\hline $\mathrm{Abr} / 10$ & 1,1 & 0,6 & 0,5 & 0,1 & 0,4 & 1,0 & 0,8 & 0,5 & 0,6 & 218 \\
\hline Perda de solo $\left(\mathrm{kg} / \mathrm{m}^{2}\right)$ & 7,0 & 5,4 & 3,6 & 5,7 & 6,5 & 9,4 & 8,1 & 8,2 & 6,8 & 1668 \\
\hline
\end{tabular}

Nota - para encontrar a densidade aparente do solo foi extraída uma média dos valores encontrados de 15 amostras com um Desvio Padrão de 0.25.

A perda de solo nos caminhos preferenciais próximos aos corpos hídricos é maior em relação aos caminhos localizados nas áreas ao longo da vertente (terras altas), (Tabela 3). A perda total foi de $6,8 \mathrm{~kg} / \mathrm{m}^{2}$, sendo $27,9 \%$ superior às perdas registradas nos caminhos localizados na vertente. Quando analisadas as perdas de solo separadamente, nota-se que os meses entre outubro e fevereiro, houve um aumento nas perdas em relação aos demais períodos. Essa variação pode ser atribuída à temperatura, pois nos meses mais quentes há uma procura maior por água para dessedentação. Outra questão que pode ter influenciado nesta variação é a utilização dos corpos hídricos como locais de "banho" pelos suínos.

Foi observado em campo que durante os períodos mais quentes os suínos passam boa parte do dia revolvendo o leito das margens e formando pequenas represas (lagoas) para se refrescarem.

Cabe considerar que os suínos são animais homeotérmicos e precisam manter a temperatura corporal relativamente constante, eles necessitam, através de variações fisiológicas, comportamentais e metabólicas, produzindo calor para aumentar a temperatura corporal quando a temperatura diminui ou perder calor para o meio diminuindo a temperatura corporal no estresse calórico (HANNAS, 1999). A característica desse tipo de animal acaba promovendo uma variação sazonal dos locais de pastoreio ao longo do ano, o que pode influenciar na variação de perda de solo nos caminhos preferenciais, pois nos períodos mais quentes esses animais precisam passar boa parte do dia no leito dos rios (Figura 4). Já nos períodos mais frios eles permanecem a maior parte do tempo nas áreas de pastagens devido à maior insolação.

\section{Uso da terra e perda de solo}

Diversas pesquisas indicam valores de perda de solo em pastagens, tais como: ELTZ et al., (1977), com perda em torno de 0,06 t/ha no Cerrado Brasileiro; Dedecek et al., (1986), que em ambiente controlado, observaram que as perdas de solo em pastagem de $B$. decumbens, sem animais, foram de 0,15 $\mathrm{t} / \mathrm{ha}$. Sorrenson e Montoya, (1989), com perdas 1,8 t/ha em Campo Mourão PR; Barbosa e Fearnside, (2000), com perdas em torno de 1,11t/ha em Roraima; Bertoni e Lombardi Neto, (2005) com perdas de 0,4 t/ha, em São Paulo.

Na região Centro-Sul do Paraná, Thomaz, (2007), encontrou valores de perda de solo entre $0,93 \mathrm{t} / \mathrm{ha}$ a $1,17 \mathrm{em}$ Guarapuava PR. Enquanto, Antoneli, (2011), monitorando uma área de Faxinal em Guamiranga-PR encontrou perdas que variaram de $0,71 \mathrm{t} / \mathrm{ha}$ a $1,34 \mathrm{t} / \mathrm{ha}$. 

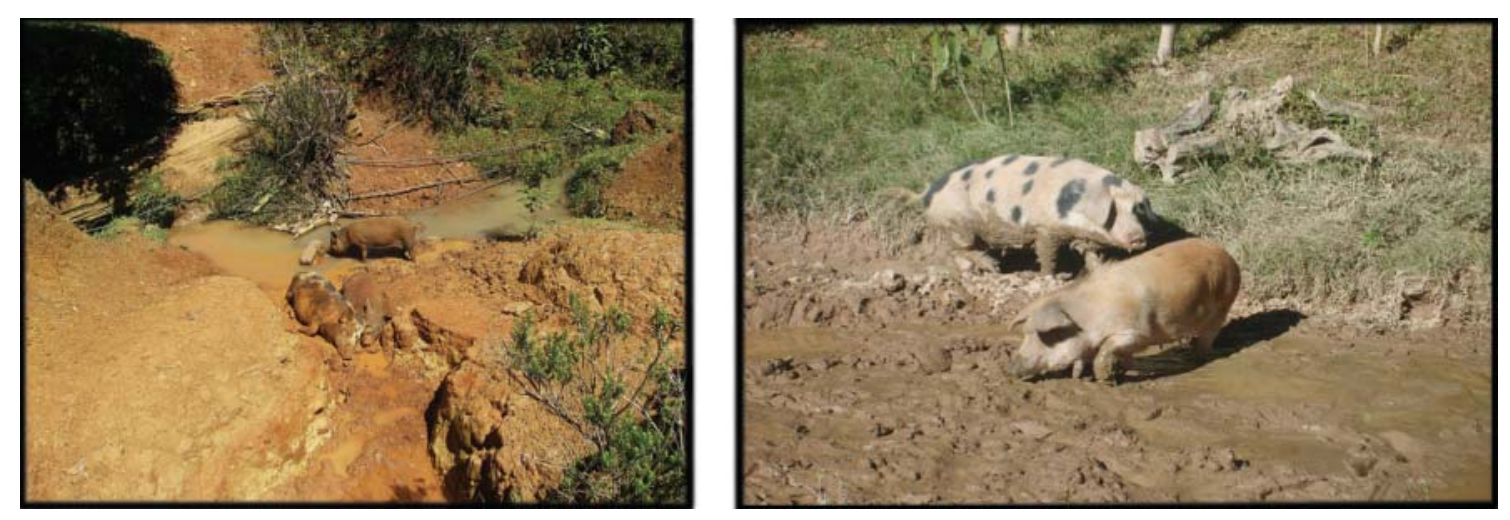

Figura 4 - Animais (suínos) utilizando os corpos hídricos para dessedentação e banho.

Quando comparada a perda de solos nos caminhos preferenciais com as perdas em áreas de pastagens, nota-se que há uma variação, pois as perdas de solo em áreas de pastagens, geralmente são inferiores a $1 \mathrm{t} / \mathrm{ha}$, especialmente, quando é afetado por erosão laminar. Contudo, quando os processos erosivos são lineares (sulcos e ravinas) a taxa de erosão atinge valores maiores (THOMAZ e DIAS, 2009).
O valor encontrado de perda de solo nos caminhos preferenciais por esta pesquisa indicou valor muito acima daqueles estimados para as áreas de pastagens, no entanto, apresentou valor próximo daquele estimado para estradas, áreas degradadas e áreas agrícolas com cultivo convencional. (Tabela 4)

Tabela 4 - Perdas de solo em diversos tipos de uso do solo.

\begin{tabular}{|c|c|c|}
\hline Fonte & Uso do solo & $\begin{array}{l}\text { Taxa de erosão }(\mathrm{kg} / \\
\left.\mathrm{m}^{2} / \mathrm{ano}\right)\end{array}$ \\
\hline DECHEN et al., (1981) & Pastagem com leguminosas & 3,5 \\
\hline RUFINO et al., (1985) & Cultura de café & 3,0 a 13,3 \\
\hline BONO et al.,(1996) & Pastagem nativa & 3,9 \\
\hline BONO et al., (1996) & Pastagem melhorada. & 2,4 \\
\hline ALBUQUERQUE et al., (2001) & Após desmatamento da caatinga & 6,1 \\
\hline INÁCIO et al., (2007) & Solo exposto em pastagens & 2,6 \\
\hline RAMOS-SCHARRÓN e MACDONALD (2007) & Segmento de estrada com nivelamento anual & 5,7 \\
\hline MARTINEZ-ZAVALA et al., (2008) & Segmento de estrada & 2,1 \\
\hline THOMAZ e ANTONELI (2008) & Área degradada (solo exposto) & 9 a 14 \\
\hline ANTONELI (2011) & Cultivo convencional do tabaco & 5,9 \\
\hline THOMAZ et al., (2011) & Barranco de estrada & 5,7 \\
\hline ANTONELI (2011) & Segmento de estrada rural sem nivelamento & 13,0 \\
\hline Este estudo & Caminhos Preferenciais em área de pastagens na vertente & 4,9 \\
\hline Este estudo & Caminhos preferenciais na zona ripária & 6,8 \\
\hline
\end{tabular}


Neste contexto, nota-se que a perda de solos em caminhos preferenciais em diversas pesquisas, passa despercebido, ou são ignorados, sendo avaliada apenas a perda de solo causada por erosão laminar, especialmente, nos setores de vertente.

\section{Influência da precipitação nas perdas de solo}

Apesar da influência da temperatura no pastoreio, conforme observado por Andrade et al., (2012), a precipitação também exerce influência nas perdas de solo nos caminhos preferenciais ao longo do ano (Figura 5). Foi observado em caminhamentos pela área de estudos que a intensificação do trânsito de animais em determinados períodos promove maior desagregação do solo no caminho preferencial. Estes caminhos acabam em alguns casos, interceptando e concentrando o fluxo superficial de água originado na vertente. Além disso, à medida que se aproximam das partes mais baixas da vertente vão adquirindo maior poder de remoção devido à maior declividade e acúmulo de água.
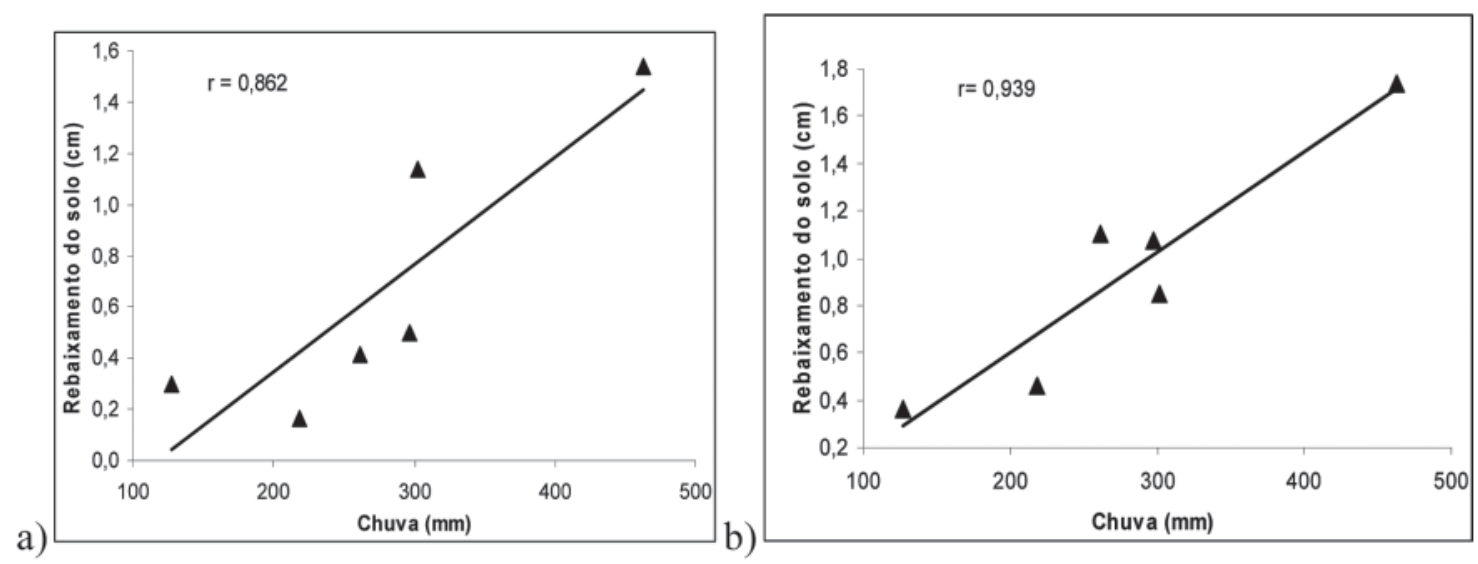

Figura 5 - correlação entre perda de solo nos caminhos preferenciais com a precipitação. a) correlação entre precipitação e a perda de solo nos caminhos preferenciais ao longo da vertente. b) correlação entre precipitação e a perda de solo nos caminhos preferenciais na zona ripária.

Verifica-se que há alta correlação entre a precipitação e a perda de solo no interior dos caminhos preferenciais ( $\mathrm{r}=0,862$ nas vertentes e $\mathrm{r}=0,939$ na zona ripária). Apesar da alta correlação, nota-se que, os caminhos preferenciais na vertente (terras altas), há redução em relação aos caminhos localizados na zona ripária (terras baixas). Esta variação pode ser atribuída à declividade, pois os caminhos próximos aos cursos de água são mais declivosos e mais largos, o que aumenta a área de coleta de água da chuva.

Foi observado em campo, que devido ao pisoteio dos animais em determinados caminhos preferenciais, formaram-se micro depressões. Com a ocorrência de precipitação de menor volume, houve um assoreamento dessas pequenas depressões. No entanto em precipitação de maior volume (>30 $\mathrm{mm}$ ), este material que havia sido depositado nestas depressões foi colocado em movimento, aumentando a carga de sedimentos.

Destaca-se também a influência da perda de solo dos barrancos dos caminhos preferenciais, que apesar de não ser individualizada sua perda, ficou evidente ao longo do monitoramento que estes sofrem influência de desmoronamento devido ao solapamento da base e do pisoteio dos animais. Ou fator que causa o colapso de material é o ciclo de expansão e contração do solo devido ao ciclo do umedecimento.

\section{Influência da sazonalidade climática no movimento de animais e na compactação do solo nos caminhos preferenciais}

Dentre os diversos efeitos, tanto diretos quanto indiretos do pastejo dos animais, a compactação, desponta como uma das principais responsáveis pelo desencadeamento dos processos erosivos em pastagens (REICHERT et al., 2007). $\mathrm{O}$ aumento ou redução do pisoteio nos caminhos preferenciais implicam na variação da compactação da superfície. (Tabela 5). 
Antoneli, V. et al

Tabela 5 - Variação da resistência do solo nos caminhos preferenciais associado a temperatura e chuva.

\begin{tabular}{lllll}
\hline & \multicolumn{1}{c}{$\begin{array}{c}\text { Resistência do solo terras altas } \\
(\mathrm{MPa})\end{array}$} & $\begin{array}{c}\text { Resistência do solo zona ripária } \\
(\mathrm{MPa})\end{array}$ & *Temperatura média $\left({ }^{\circ} \mathrm{C}\right)$ & Chuva (mm) \\
\hline Jun/09 & $4,5 \pm 0,28^{* *}$ & $3,1 \pm 0,18$ & 12,8 & 127 \\
Ago/09 & $4,2 \pm 0,31$ & $3,2 \pm 0,13$ & 15,0 & 302 \\
Out/09 & $4,1 \pm 0,19$ & 18,0 & 463 \\
Dez/09 & $3,9 \pm 0,42$ & $21,8 \pm 0,27$ & 297 \\
Fev/10 & $3,8 \pm 0,38$ & $4,3 \pm 0,21$ & 22,4 & 261 \\
Abr/10 & $4,1 \pm 0,46$ & $4,5 \pm 0,34$ & 16,8 & 218 \\
\hline Média & 4,0 & $3,6 \pm 0,38$ & 17,7 & 1668 \\
\hline
\end{tabular}

Nota- * dados secundários. Fonte: Andrade et al., (2012). ** o Desvio Padrão refere-se ao total de amostras coletadas em cada campanha $(n=120)$

Quando analisada a Tabela 5, nota-se que a resistência da superfície dos caminhos preferenciais varia de 3,1 $\mathrm{MPa}$ (menor resistência) à 4,5 $\mathrm{MPa}$ ( maior resistência). A resistência do solo na vertente (terras altas), indicou um média de 4,0 $\mathrm{MPa}$, variando de 3,8 a 4,5 MPa. Enquanto que a resistência do solo na zona ripária (terras baixas, indicou uma média em torno de 3,7 MPa, com variação entre 3,1 a 4,5 MPa.

Verifica-se também, que há variação na compactação do solo ao longo do período de monitorado, sendo que nos períodos mais frios (junho a agosto), ocorreu maior compactação do solo nos caminhos preferenciais existentes nas vertentes (terras altas), (4,5 MPa e 4,2 MPa respectivamente). Em contrapartida, houve uma redução da resistência do solo nos caminhos preferenciais na zona ripária (terras baixas). Esta variação pode ser atribuída a maior movimentação dos animais nas áreas de pastagens nas terras altas nos períodos mais frios, pois devido às geadas que são frequentes nestes períodos, há uma redução do pasto, o que implica em maior mobilização dos animais a procura de alimento, além de permanecer maior parte do tempo exposto ao sol.

Entre os meses de outubro e dezembro, observou-se que foi ocorrendo uma inversão na compactação do solo, ou seja, os caminhos preferenciais nas pastagens das terras altas foram reduzindo enquanto os caminhos que dão acesso aos corpos hídricos (terras baixas), foram indicando valores maiores de compactação. Esta inversão pode ser atribuída a alguns fatores, tais como: aumento da procura dos animais por água para a dessedentação; utilização dos corpos hídricos para redução da temperatura corporal dos suínos.

A redução da compactação nas pastagens nos períodos mais quentes pode ser atribuída às condições climáticas, pois com o aumento da temperatura, há um aumento no volume de biomassa do pasto, devido a rebrota, além dos animais passarem boa parte do dia a sombra ou próximo aos corpos hídricos. O consumo de alimentos por animais em pastejo diminui quando a temperatura ambiente ultrapassa $26^{\circ} \mathrm{C}$ (FERREIRA, 2005).

Já Widowski (2001), ao observar durante 24 dias, o pastejo de vacas e bezerros de corte em pastagens com e sem acesso à sombra nos Estados Unidos, concluiu que o tempo gasto à sombra foi proporcional à temperatura do ar. Segundo o autor, animais sem acesso à sombra passavam maior tempo próximo ao bebedouro. JOHNSON e STRACK (1992), ao pesquisarem grupos de carneiros na Austrália, com maior ou menor uso voluntário de sombra na pastagem, não apresentaram diferença quanto ao tempo dedicado ao pastejo, no entanto, segundo os autores, animais à sombra permaneciam deitados, duas horas a menos por dia que animais ao sol, o que implicou em maior mobilização.

O tempo de pastejo em um sistema silvopastoril foi estudado por PAES LEME et al. (2005), que observaram o comportamento de bovinos no verão e no inverno quanto ao tempo deitados e em pé. Segundo os autores, no inverno, o gado fica $19,3 \%$ do tempo deitado no sol e 6,2\% deitado à sobra, sendo que $38,2 \%$ ficam em pé ao sol e $36,4 \%$ a sombra. Já no verão, apenas $5,0 \%$ do tempo o gado fica deitado ao sol e $17,5 \%$ deitado na sombra, sendo que $26,4 \%$ do tempo ficam em pé ao sol e $51,1 \%$ fica em pé a sombra. Essa variação implica em diferente pressão sobre as condições do solo ao longo do ano.

A revisão de literatura dá suporte para o entendimento da mobilização dos animais ao longo do ano. Sendo que essa mobilização influencia diretamente nas perdas de solo e compactação dos caminhos preferenciais tanto nas terras altas, quanto nos caminhos próximos aos corpos hídricos (corpos hídricos). Dessa forma, a relação entre o comportamento animal e processos geomorfológicos estão intimamente ligados (biogeomorfologia). 


\section{Conclusão}

Por meio do monitoramento de caminhos preferenciais em áreas de faxinais nas vertentes (terras altas) e na zona ripária (terras baixas), conclui-se que a perda de solo nestes locais muitas vezes não é levada em consideração nas pesquisas, sendo considerada apenas a perda de solos nas pastagens. Conclui-se que a perda de solo nestes caminhos preferenciais está próxima daquelas encontradas por diversos pesquisadores em estradas, áreas degradadas e áreas agrícolas com cultivo sem práticas conservacionistas.

As perdas de solo nos caminhos preferenciais nas vertentes (terras altas) apresentaram menor valor em relação à perda de solo nos caminhos preferenciais próximos aos corpos hídricos (terras baixas), o qual pode ser atribuído à redução do pisoteio em determinados períodos do ano, além da menor declividade. Já nos caminhos na zona ripária, as perdas foram maiores $(27,9 \%)$. Este aumento pode ser atribuído a maior concentração de animais nos períodos mais quentes. Conclui-se também que esta perda pode ter sido causada pela maior umidade nestes caminhos, causada pelo contado dos animais com os corpos hídricos, que ao "deixarem" o rio após a sedentação e/ou banho, promovem um lamaçal no caminho preferencial, facilitando a remoção deste material durante as chuvas.

A compactação dos caminhos preferenciais nas vertentes (terras altas) indicou valores maiores nos períodos mais frios, enquanto que nos períodos mais quentes, houve redução da compactação nestes caminhos. Já nos caminhos preferenciais na zona ripária (terras baixas), houve uma variação contrária, ou seja, nos períodos mais frios indicou menor compactação, já nos períodos mais quentes, houve um aumento na compactação do solo nestes caminhos.

Essa alternância pode ser explicada pela variabilidade da temperatura ao longo do ano, que pode influenciar na quantidade de biomassa disponível para o pastejo, além da utilização dos corpos hídricos pelos animais com maior frequência nos períodos mais quentes.

Contudo, conclui-se, que estes caminhos preferenciais são importantes conectores de sedimentos e água das vertentes para os corpos hídricos, além de serem importantes produtores de sedimentos e que merecem maior atenção dos pesquisadores ao avaliar as perdas de solos em áreas de pastagens. Conclui-se também, que esta pesquisa irá contribuir para um repositório de informações acerca da Biogeomorfologia que ainda é pouco difundida no Brasil, mas que merece destaque a ação dos animais como agentes em potencial para alteração dos processos geomorfológicos atuantes em vertentes.

\section{Referências bibliográficas}

ALBUQUERQUE, J. M. de. Florística, Estrutura e aspectos físicos de Floresta ombrófila Mista em sistema Faxinal no Município de Rebouças-PR. Dissertação (Mestrado) Universidade Estadual do Centro-Oeste- UNICENTRO. 2009. 93 p.

ALBUQUERQUE, A.W.; LOMBARDI NETO, F. \& SRINIVASAN, V.S. Efeito do desmatamento da caatinga sobre as perdas de solo e água de um Luvissolo em Sumé (PB). R. Bras. Ci. Solo, 25:121-128, 2001

ANTONELI, V. Mudanças no uso do solo promovidas pela extinção do sistema de Faxinal - estudo de caso da bacia do Arroio Boa Vista - Guamiranga - PR. ANAIS.. Simpósio Internacional de Geografia Agrária 3 e Simpósio Nacional de Geografia Agrária 5 "Jornada Orlando Valverde" Campesinato em Movimento Londrina-PR. UEL. pg 1 -19, 2007.

ANTONELI, V. Dinâmica do uso da terra e a produção de sedimentos em diferentes áreas fontes na bacia hidrográfica do Arroio Boa Vista- Guamiranga-PR. Tese (Doutorado em Geografia) Universidade Federal do Paraná - UFPR. Curitiba 2011. 354

ANDRADE, A.R.; ANTONELI, V. BEDNARZ, J.A. Comparação da dinâmica geomorfoclimatica entre áreas florestadas e de pastagens com influência da migração de animais no Faxinal Marmeleiro de Cima - Rebouças-PR. Caderno Prudentino de Geografia. 2012 (aceito para publicação)

ARAÚJO FILHO, J. A. de; CARVALHO, F. C. Sistemas de produção agrossilvipastoril para o semi-árido nordestino. In: CARVALHO, M. M.; ALVIM, M. J.; CARNEIRO, J. C. (Ed.). Sistemas agroflorestais pecuários: opções de sustentabilidade para áreas tropicais e subtropicais. Juiz de Fora, MG: Embrapa Gado de Leite, 2001. p.101-110.

BARBOSA R.I.; FEARNSINE, F.M. Erosão de solos na Amazônia: estudo de caso da Região Apiaú Roraima Brasil. Acta Amazônica 30 (04) 601-613. 2000.

BERTONI, J. E LOMBARDI NETO, F. Conservação do solo. $5^{a}$ edição, ícone Editora, São Paulo. 355p. 2005.

BONO, J.A.M.; CURI, N.; FERREIRA, M.M.; EVANGELISTA, A.R.; CARVALHO, M.M. \& SILVA, M.L.N. Cobertura vegetal e perdas de solo por erosão em diversos sistemas de melhoramento de pastagens nativas. Past. Trop., 18:2-8, 1996.

BOOYSEN, P.V.; TAINTON, N.M.; SCOTT, J.D. Shootapex development in grass and its importance in grassland management. Herbage abstracts, 33:209-13, 1963

CHANG, M. Y. Faxinais no Paraná. Informe de pesquisa, $n$. $^{\circ}$ 80. Londrina: IAPAR, 1986.

CARVALHO, H. M. de. DaAventura à Esperança: AExperiência Autogestionária no Uso Comum da Terra. Curitiba, 1984.

COALDRAKE, J. E.; TOTHILL, J. C.; GILLARD, P. Natural vegetation and pasture research. In:Tropical pasture resarch. Principles and Methods. Ed. N. H. SHAW and W. M. BRYAN. Commonwedth Agricultural Bureaux, Berkshire, England, 1976. pp. 51-76.

COGO, N. P.; LEVIEN, R.; SCHWARZ, R. A. Perdas de solo e água por erosão hídrica influenciadas por métodos de preparo, classes de declive e níveis de fertilidade do solo. R. Bras. Ci. Solo, v. 27, n. 4, p. 743-753, 2003. 
DECHEN, S.C.F.; LOMBARDI NETO, F. \& CASTRO, O.M. Gramíneas e leguminosas e seus restos culturais no controle da erosão em Latossolo Roxo. R. Bras. Ci. Solo, 5:133-137, 1981.

DEDESEK, R.A.; RESK, D.U.S.; FREITA JUNIOR, A. Perdas de solo, água e nutrientes por erosão, em latossolo vermelhoescuro sob cerrado em diferentes cultivos sob chuva natural. R. Bras. Ci. Solo,, v.10, n. 3, p. 265-272, 1986.

DORETTO, M. Caracterização do processo de diferenciação camponesa na modernização capitalista: o caso da microrregião colonial de Irati - PR. Dissertação (mestrado) UFPB. Campina Grande: Universidade Federal da Paraíba, 1992.

ELTZ, F. L. F., COGO, N. P., MIELNICZUK, J. Perdas por erosão em diferentes manejos de solo e coberturas vegetais em solo Laterítico Bruno-avermelhado distrófico (São Jerônimo). I. Resultados do primeiro ano. R. Bras. Ci. Solo,, v. 1, n. 2-3, p. 123-127, 1977.

EMBRAPA. Serviço Nacional de Levantamento de Solos. Levantamento dereconhecimento dos solos do Estado do Parana. Boletim tecnico, n. 27. Convenio SUDESUL, EMBRAPA, IAPAR. Londrina: EMBRAPA: IAPAR, 1984.

FERREIRA, R. A. Maior produção com melhor ambiente para aves, suínos e bovinos. Viçosa, MG: Aprenda Fácil, 2005. 371p.

HANNAS, M.I. Aspectos fisiológicos e a produção de suínos em clima quente. In SILVA, I.J.O. Ambiência e qualidade na produção industrial de suínos. Piracicaba. FEALQ. 1999. p 01- 33.

HOLT, J. A.; BRISTOW, K. L.; McIVOR, J. G. The effects of grazing pressure on soil animails and hydraulic properties of two soils in semi-arid tropical Queensland. Journal of Soil Research, 34, 69-79, 1996.

HUDSON. N. W. Field measurementof soil erosion and runoff. FAO, Soils bulletin. Rome, n. 68, 1993. 139p.

INÁCIO, E. dos S. B.; CANTALICE, J. R. B.; NACIF, P. G. S.; ARAÚJO, Q. R. de; BARRETO, A. C. Quantificação da erosão em pastagem com diferentes declives na microbacia do Ribeirão Salomea R Bras. de Eng. Agr. e Amb. vol.11 n.4 Campina Grande July/Aug. 2007.

JOHNSON, K. G.; STRACK, R. Effects of shade use on grazing, drinking, ruminating and postural patterns of Merino sheep. Australian Journal of Agricultural Research, v. 43, p. 261-264, 1992.

MAACK, R. Geografia física do Paraná. Rio de Janeiro: José Olympio, 1968.

MARTÍNEZ-ZAVALA, L.; LÓPEZ, A. J.; BELLINFANTE, N. Seasonal variability of runoff and soil loss on forest road backslopes under simulated rainfall. Catena, n. 74, p.73-79, 2008.

MINEROPAR. Atlas geomorfológico do Estado do Paraná Escala 1:250.000 modelos reduzidos; Universidade Federal do Paraná. Curitiba.2006.

MONTEIRO, F. A. \& WERNER, J. C. Ciclagem de nutrientes minerais em pastagens. Anais.. In: Simpósio sobre ecossistema de pastagens.Ed. V. FAVORETTO; L. R. A. RODRIGUES, Jaboticabal, FUNEP, 1989. PP. 147-92.

MOTA, et.al. Qualidade e atributos físicos de um Latossolo Vermelho Distroférrico típico em diferentes sistemas de manejo Revista Agrárian Dourados, v.4, n.12, p.105-112, 2011
MULLER, M. M. L.; GUIMARÃES, M. F.; DESJARDINS, T. Degradação de pastagens na Região Amazônica: propriedades físicas do solo e crescimento de raízes. Pesquisa Agropecuária Brasileira, 36, 1409-1418, 2001

PAES LEME, T. M. S.; PIRES, M. F. A.; VERNEQUE, R. S. et al. Comportamento de vacas mestiças holandês $\mathrm{x}$ zebu, em pastagem de Brachiaria decumbens em sistema silvipastoril. Ciênc. Agrotec., Lavras, v.29, n.3, p.668-675, maio/jun., 2005.

PERUCELI M ; ANTONELI, V. . Produção de serrapilheira em uma floresta ombrófila mista sob o domínio do sistema de faxinal; estudo de caso do Faxinal de Papanduva de BaixoPrudentópolis-PR.. In: XVI Encontro Nacional de Geógrafos, 2010, Porto alegre Anais... URGS, 2010. v. 1.

RAMOS-SCHARRÓN, C.E.\&MACDONALD,L.H. Measurement and prediction of natural and anthropogenic sediment sources, St.John, U.S. Virgin Islands. Catena, n. 71, p. 250-266, 2007.

REICHERT, J. M.; SUZUKI, L. E.A. S; REINERT, J. D. Compactação do solo em sistemas agropecuários e florestais: identificação, efeitos, limites críticos e mitigação. Tópicos Ci. Solo, 5:49-134, 2007

RUFINO, R.L.; HENKLAIN, J.C. \& BISCAIA, R.C.M. Influência das práticas de manejo e cobertura vegetal do cafeeiro nas perdas de solo. R. Bras. Ci. Solo, 9:277-280, 1985.

SILVA FILHO, E. P.; CARNEIRO, E. X.; CARNEIRO, C. Avaliação da compactação de solos em áreas de pastagem no Município de Porto Velho-RO-Amazônia Ocidental. Primeira Versão, ano II, n. 1082002

SNAYDON, R. W. The ecology of pastures. In: Grazing Animals. Ed. F.H.W. MORLEY, Elsevier Scientific Publishing Company. Amsterdam, 1981. pp. 13-31.

SORRENSON, W. J.; MONTOYA, L.J. Implicações econômicas da erosão e do uso de algumas práticas conservacionistas no Paraná. Boletin Técnico n. 21 Londrina IAPAR. 1989. 110 p.

SUDERHSA - Superintendência de Desenvolvimento de Recursos Hídricos e Saneamento Ambiental. Atlas de recursos hídricos do Estado do Paraná. Curitiba: SUDERHSA, 1998, p. 7-11.

THOMAZ.E.L; ANTONELI.V. Erosão e degradação do solo em área cultivada com erva-mate (illexparaguariensis)- GuarapuavaPR. São Paulo. UNESP. Geociências vol.27, n1. p. 21-31. 2008

THOMAZ, E. L.; ANTONELI, V. DIAS, W. A. Estimativa de Proveniência de Sedimento em Cabeceira de Drenagem com Alta Densidade de Estradas Rurais não Pavimentadas Revista Brasileira de Recursos Hídricos Volume 16 n.2 - Abr/Jun 2011, 25-37

THOMAZ, E. L. Dinâmica do uso da terra e degradação do solo na bacia do Rio Guabiroba - Guarapuava/PR. RA'E GA, n. 13, p. 109-128, 2007.

THOMAZ, E. L.; DIAS, W. A. Bioerosão - evolução do rebanho bovino brasileiro e implicações nos processos geomorfológicos. Revista Brasileira de Geomorfologia, v. 10, n. 2, p. 3-11, 2009.

WIDOWSKI, T. M. Shade-seeking behavior of rotationallygrazed cows and calves in a moderate climate. In: STOWELL, R. R., BUCKLIN, R.;BOTTCHER, R. W. In: INTERNATIONAL SYMPOSIUM, 6th., 2001. Proceedings...Louisville, Kentucky, USA: ASABE, 2001. p. 632-639. 